Giulian, B. B., Singh, L. M., Mansfield, A. O., Pairent, F. W., and Howard, J. M. (1967). Annals of Surgery, 165, 564 .

Glaessner, K., and Sigel, J. (1904). Berliner klinische Wochenschrift, 41, 440. Goebell, H., and Bode, C. (1969). Medizinische Welt, 15, 877.

Haro, E. N., and Faloon, W. W. (1964). Clinical Research, 12, 207.

Harris, R., Norman, A. P., and Payne, W. W. (1955). Archives of Disease in Childhood, 30, 424 .

Hennrich, N., Hoffman, A., and Lang, H. (1965). Arzneimittel-Forschung, $15,434$.

Jordan, P. H., jun., and Grossman, M. I. (1959). Gastroenterology, 36, 447.

Kivirrikko, K. I., Laitinen, O., and Prockop, D. J. (1967). Analytical Biochemistry, 19, 249.

Kugener, H., Bergman, O., and Beck, K. (1968). Zeitschrift für Gastroenterologie, 6,430 .
Matthews, L. W., and Spector, S. (1961). Pediatrics, 27, 351.

May, C. D., and Lowe, C. U. (1949). Fournal of Pediatrics, 34, 663.

Mullinger, M. (1968). Pediatrics, 42, 523.

Nusser, E., and Donath, H. (1968). Medizinische Klinik, 63, 142.

Pairent, F. W., Trapnell, J. E., and Howard, J. M. (1969). Annals of Surgery, 170,737 .

Prockop, D. J., Keiser, H. R., and Sjoerdsma, A. (1962). Lancet, 2, 527.

Schultis, K., and Wagner, E. (1968). Deutsche medizinische Wochenschrift, 93, 1685 .

van de Kamer, J. H., ten Bokkel Huinink, H., and Weyers, H. A. (1949). fournal of Biological Chemistry, 177, 347 .

Veeger, W., Abels, J., Hellemans, N., and Nieweg, H. O. (1962). New England fournal of Medicine, 267, 1341.

\title{
Use of Amantadine in Parkinson's Disease. Results of a Double-blind Trial
}

VERA DALLOS, ${ }^{*}$ M.B., в.S., в.SC. ; KENNETH HEATHFIELD, † M.D., F.R.C.P. ; PATRICIA STONE, $\ddagger$ B.PHARM., M.P.S. F. A. D. ALLEN, $\subseteq$ F.P.S., D.B.A.

British Medical fournal, 1970, 4, 24-26

ummary: In a four-week double-blind trial of 62 patients with Parkinsonism 29 were treated with amantadine and 33 with a placebo. Modest but statistically significant improvement was observed in the first group, optimum benefit occurring after the first two weeks. Patients' reactions to the drug were favourable in $79 \%$, and side effects were insignificant. Though amantadine appears to be a useful additive drug in the treatment of Parkinsonism, its value as a single treatment is as yet undetermined.

\section{Introduction}

Schwab, England, Poskanzer, and Young (1969) observed the beneficial effect of amantadine in a patient with Parkinsonism who had been given the drug as a prophylactic against influenza. They subsequently reported its use in 163 cases. Their observations have since been confirmed by Parkes, Zilkha, Calver, and Knill-Jones (1970) in a controlled trial of 37 patients treated for two weeks.

The aim of the present study was to investigate a larger group of patients and to determine the place of amantadine in the treatment of Parkinsonian symptoms.

\section{Patients and Methods}

Sixty-two outpatients ( 24 men and 38 women) with Parkinsonism were admitted to trial. Twenty-nine were allocated randomly to receive amantadine and 33 to receive placebo capsules. The randomization was stratified with regard to age, sex, previous thalamotomy, and initial severity, as judged by our scoring system for rigidity, tremor, akinesia, and functional disability, and for tests of motor facility (occupational therapy tests). The age of the patients ranged from 43 to 74 years in the amantadine group (group A) and from 40 to 74 years in the placebo group (group B). There were 10 men (34\%) in group $A$ and $14(43 \%)$ in group $B$.

Out of the 62 patients, 58 completed the trial-28 in group A and 30 in group B. One patient in group A died of pneumonia and three in group $B$ failed to attend after the initial assessment, after the second week, and after the third week, respectively. In group A 17 cases were judged to be of idiopathic paralysis agitans, five were arteriosclerotic, and six post-encephalitic; seven patients had had previous thalamo-

\footnotetext{
* Medical Registrar.

† Consultant Neurologist.

$\ddagger$ Deputy Chief Pharmacist.

Group Pharmacist.

Whipps Cross Hospital, London E.11.
}

tomy. In group B 17 cases were idiopathic, six arteriosclerotic, and seven post-encephalitic; nine patients had had previous thalamotomy.

Scores for severity of tremor, rigidity, and akinesia were given by a clinical observer and those for functional disability and occupational therapy tests were allocated by the occupational therapist. Neither the clinician nor the occupational therapist knew which patients were on the test drug; this was known only by the pharmacist who dispensed the capsules according to the instructions of the statistician.

\section{Scoring System}

Scores for severity of rigidity and tremor were allotted on the following basis: severe $=3$, moderate $=2$, slight $=1$, and nil $=0$. Severity of rigidity and tremor were recorded for each of the four limbs and for the trunk. The possible total score for each sign was 15 .

Akinesia was assessed by nine factors: eight on a threepoint severity scale $(0,1$, or 2$)$ and one on a five-point scale $(0,1,2,3$, or 4$)$, the total score being 20 :

$\begin{array}{ll}\text { Mask-like facies } & 0-2 \\ \text { Dribbling } & 0-2 \\ \text { Shuffling gait } & 0-2 \\ \text { Festination } & 0-2 \\ \text { Feet stick to ground } & 0-2 \\ \text { Attitude of flexion } & 0-2 \\ \text { Loss of arm swinging } & \\ \text { (R) } & 0-2 \\ \text { (L) } & 0-2 \\ \text { Weak voice } & 0-4\end{array}$

Assessments were made at weeks $0,1,2,3,4$, and 8 by the clinician.

Social disability was assessed by 10 aspects on a threepoint severity scale $(0,1$, or 2$)$ :

$\begin{array}{ll}\text { 0 points: } & 1 \text { point: } \\ \text { (1) Fully employed } & \text { Light job }\end{array}$

(2) Uses public trans- Light job

port

(4) Can cross road

(5) Can climb stairs

(6) Can dress

(7) Arise from chair

(8) Feeds himself

(9) Can turn over
(10) Not confined to chair

Six occupational therapy tests were given according to speed of performance, each on a six-point scale (0-5) giving a possible total of 30 points:

$$
\begin{aligned}
& \text { Threading beads } \\
& \text { Removing beads } \\
& \text { Peg board-large } \\
& \text { Peg board-small } \\
& \text { Handwriting } \\
& \text { Gait }
\end{aligned}
$$


Assessments were made by the occupational therapist at weeks 0,4 , and 8 . Each assessment by the clinician and by the occupational therapist gave a total of 50 possible disability scores. The patient's subjective assessment and side effects were also recorded. Analysis was done by an independent statistician.

\section{Drugs}

The amantadine (100 mg.) and placebo were presented in identical red capsules and were taken each morning and midday for four weeks. The patients continued to take their other anti-Parkinsonian drugs throughout the period of the trial. After four weeks amantadine or placebo was withdrawn and the patients were reassessed at eight weeks. The patients were instructed to bring back their remaining capsules (for counting).

\section{Results}

For the purpose of statistical analysis the progress of the two groups was expressed as percentage of the initial disability. The initial score was taken as 100 and the actual initial disability scores are given in parentheses in Table I. Figures below 100 indicate improvement and figures above 100 deterioration.

TABLE I

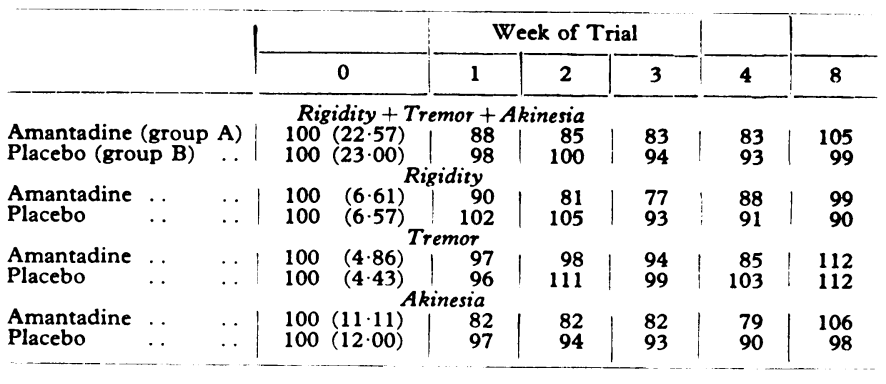

\section{Combined Scores}

The combined scores for rigidity, tremor, and akinesia in group A fell slightly in the first week, more in the second, third and fourth weeks. The greatest advantage over group B occurred at weeks 1 and 2 , when it reached statistical significance at $P<0.01$. The improvement at four weeks was not statistically significant, though group $\mathrm{A}$ improved $17 \%$ against $7 \%$ in group $\mathbf{B}$.

Rigidity.-Group A improved steadily over weeks 1, 2, and 3 ; the best week for rigidity being week 3 . Statistically significant advantage over group B, however, occurred at week 2 only $(P<0.01)$ and reaching only borderline significance at week $3(0.1>P>0.05)$. At week 4 group A showed $12 \%$ improvement against $9 \%$ improvement of group B.

Tremor.-Though consistent improvement was shown throughout the treatment period it was only moderate, no significant advantage to group A being found.

Akinesia.-In group A statistically significant improvement occurred during the first week $(0.05>P>0.02)$, but at week 2 the difference between group $\mathrm{A}$ and $\mathrm{B}$ was only of borderline significance $(0.1>P>0.05)$. At weeks 3 and 4 the difference was within the range of chance $(0 \cdot 2>\mathrm{P}>0 \cdot 1)$.

With one exception (rigidity, group B) all indices returned to the original level at week 8 .

Less improvement was apparent in the scores of disability and in the occupational therapy tests than in those of rigidity, akinesia, and tremor, but improvement occurred only in the amantadine group (Table II). We were disappointed that these tests, originally designed to assess improvement
TABLE II.-Disability and Occupational Therapy Tests. Mean Scores at Weeks 4 and 8 as Percentages of Initial Scores in Parentheses

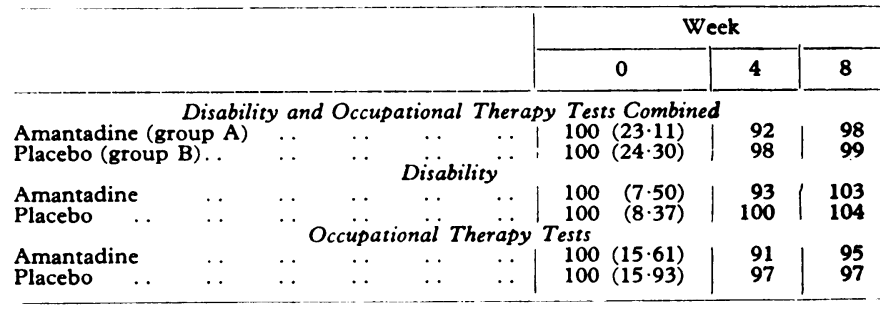

after stereotaxis, appeared less sensitive than the clinical observations.

\section{Subjective Findings}

Subjective impressions were obtained from all the patients. In group $A$ (28 patients) 22 thought that the drug had helped and six did not think it had done so. In group B (30 patients) nine received subjective benefit while 21 did not. This difference is significant $(P<0.01)$. The preference for amantadine was also observed in the pharmacy, as all the patients on it took their capsules regularly, while four patients on placebo took them irregularly and three others failed to complete the trial.

Side Effects.-Side effects from amantadine were few and none was important; more patients taking placebo complained of side effects than those on the drug. Side effects from amantadine included dry mouth in four patients, drowsiness one to two hours after taking the tablets in three, and blurred vision in two. Two patients complained of giddiness-in one of them this was due to postural hypotension. Sleeplessness was reported in one patient. All these side effects disappeared after four weeks' treatment with the drug. Two patients developed visual hallucinations; both were coincidentally taking benzhexol. These responded to reduction of the dose of benzhexol.

\section{Discussion}

The results show the superiority of amantadine to placebo in alleviating various facets of Parkinson's disease. More benefit was obtained in relief of akinesia and rigidity than of tremor. Tremor is difficult to assess in outpatients as it is unfavourably influenced by hospital attendance and many patients stated that their tremor was less pronounced at home. The patients' reactions to the drug were favourable in $79 \%$, a figure similar to that found by Parkes et al. (1970).

We were impressed by the speed of action of amantadine, optimum benefit occurring after the first two weeks of treatment. This finding is in agreement with that of Parkes et al. By the fourth week, however, benefit was less significant and a decline in benefit was evident. The mechanism of this falling off needs further investigation. Two patients obtained more than $50 \%$ benefit with the drug. No comparable degree of improvement was obtained in those of group B. Such an improvement evident in two weeks makes a trial of this drug worth while. We found no relationship between response and aetiology. Like previous workers we found that tremor responded less well than akinesia, and therefore consider that stereotaxis has a major role to offer the younger patient with unilateral Parkinson's disease.

Side effects on a $200-\mathrm{mg}$. daily dose were insignificant and disappeared with continued medication. While some side effects resembled th $e$ of the anticholinergic drugs-for example, blurred vis:on and dry mouth-one patient had postural hypotension sesembling the effect of L-dopa (Calne et al., 1970). Only cr. patient complained of excitement and sleeplessness. Summation with benzhexol or orphenadrine 
may cause visual hallucinations, and reduction of the dose of these drugs may be needed when amantadine is prescribed.

All patients except two were taking conventional antiParkinsonian drugs and the trial established the additive value of amantadine. Its value as a single treatment for Parkinsonism is as yet undetermined (Alstead, 1970).

Our thanks are due to Dr. Allan Galbraith, of Geigy Ltd., who supplied the capsules, and to Dr. E. Lewis-Faning for the statistics. Thanks are also due to Mrs. Pearson and her team in the occupational therapy department and to Sister Stafford of the outpatient department. We would like to thank Dr. Eric Dormer, Dr. Eric Frankel, and Dr. A. A. G. Lewis, who kindly offered us patients under their care for trial; and Dr. D. Scott, of the London Hospital, for his advice. We also thank the North-east Metropolitan Regional Hospital Board for their contribution from the research fund.
ADDENDUM.-Since this paper was written two further articles have been published: K. R. Hunter, G. M. Stern, D. R. Laurence, and P. Armitage (Lancet, 1970, 1, 1127) and J. D. Parkes, K. J. Zilkha, P. Marsden, R. C. H. Baxter, and R. P. Knill-Jones (Lancet, 1970, 1, 1130). The paper by Hunter et al. confirmed our results of the limited use of amantadine in Parkinsonism.

REFERENCES

Alstead, S. (1970). Lancet, 1, 522.

Calne, D. B., Brennan, J., Spiers, A. S. D., and Stern, G. M. (1970). British Medical fournal, 1, 474.

Parkes, J. D., Zilkha, K. J., Calver, D. M., and Knill-Jones, R. P. (1970). Lancet, 1, 259.

Schwab, R. S., England, A. C., Poskanzer, D. C., and Young, R. R. (1969). Fournal of the American Medical Association, 208, 1168.

\title{
Postoperative Pulmonary Atelectasis and Collapse, and its Prophylaxis with Intravenous Bicarbonate
}

\author{
M. O'DRISCOLL, * F.R.c.s.
}

\begin{abstract}
Cummary: Of 181 patients undergoing major abdomi$\checkmark$ nal surgery 116 developed chest complications associated with a metabolic acidosis, low $\mathrm{PcO}_{2}$, depressed tidal volume, increased respiratory rate, but no increase in minute volume. In a matched group of $\mathbf{1 1 6}$ patients given intravenous bicarbonate postoperatively only 15 developed chest complications. This suggests that respiratory physiological dead space decreases in patients with pulmonary collapse and atelectasis following surgery. Acidotic resviration proved inefficient in the postoperative period, and intravenous bicarbonate had a very pronounced effect on the tidal and minute volumes of acidotic patients with pulmonary collapse and atelectasis.
\end{abstract}

\section{Introduction}

Chest complications following paramedian incisions in the abdomen, and particularly those following gastric surgery, increase mortality and morbidity in the postoperative period. Their incidence, which has not fallen as dramatically as expected with the recent improvements in anaesthesia and surgery, varies from $85.6 \%$ (Collins et al., 1968) to $34 \%$ (Palmer, 1955) and 30\% (Stringer, 1947). The causes of these complications include position alone (Prys-Roberts $t$ t al., 1967), infection (Collins et al., 1968), diaphragmatic and abdominal splinting (Nunn et al., 1965), pneumoperitoneum, decrease in pulmonary compliance (Lewis and Welch, 1965), reduction of respiratory amplitude (Ngai, 1967), and loss of periodic deep inspiration under anaesthesia (Bendixen et al., 1964). The problem is certainly multifaceted, and the answer complex.

I undertook this study after observing that patients who had a metabolic acidosis on the first postoperative day were those who developed atelectasis and lobar collapse. Therefore if it was possible to prevent this acidosis the incidence of chest complications might fall.

\section{Patients and Methods}

The study group, comprising 181 patients undergoing major abdominal surgery, was divided randomly into two

\footnotetext{
- Lecturer in Orthopaedics, Bristol Royal Infirmary, Bristol.
}

groups. These were not matched for age, sex, or severity of the surgical procedure. All the patients came from the same group of wards and received identical nursing care and physiotherapy. The same surgeons, anaesthetists, and nursing teams carried out the operations, no record being made of individual variation in technique; all operations lasted at least three-quarters of an hour.

The two groups were comparable in age, sex distribution, and type of operation, analgesia, and anaesthetic technique, the only difference being that the control group (group 1) did not receive intravenous bicarbonate, whereas the other group (group 2) did (Table I).

Bicarbonate.-All the patients in group 2 received $100 \mathrm{mEq}$ of sodium bicarbonate (an $8.4 \%$ solution prepared by the pharmacological department of St. James's Hospital), which was infused intravenously in 10 minutes, two hours after surgery and then eight-hourly for two doses, a total of $300 \mathrm{mEq}$ being given in the first 18 hours postoperatively. This rate of infusion was arrived at empirically, as the dangers of overrapid infusion are well known, and too slow a rate has no effect on acid-base balance.

Preoperative Assessment.-This was based on routine physical examination, history-taking, and chest radiographs. Tidal

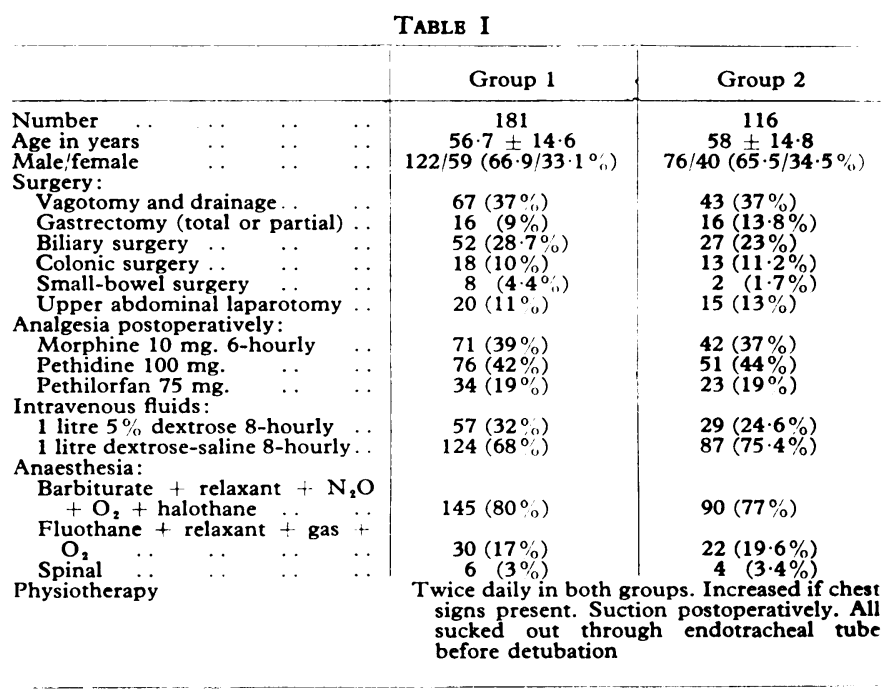

